\title{
DEVELOPMENT OF AN INTEGRATED ANP MULDIMENSIONAL DECISION MODEL TO ASSESS HEALTH TECHNOLOGIES
}

\author{
Laura Petrillo* \\ Clinical Engigneer \\ AUSL Roma E \\ Roma, RM, ITALY \\ E-mail: laura.petrillo@ausl-rme.it \\ Fabio De Felice \\ University of Cassino \\ Faculty of Engineering \\ Cassino, FR, ITALY \\ E-mail: defelice@unicas.it \\ Antonella Petrillo \\ University of Cassino \\ Faculty of Engineering \\ Cassino, FR, ITALY \\ E-mail: a.petrillo@unicas.it
}

\begin{abstract}
With health expenditures taking a growing share of gross domestic products, governments have recognized the importance of better assessing new health technologies. Policy makers, hospital administrators and other decision makers who need reliable information to reduce the uncertainty around the adoption of these technologies have turned to health technology assessment (HTA) bodies for information and advice on how to better manage, replace and exploit technologies to their full potential, and thereby ensure the adoption and diffusion of more cost-effective technologies.

Health care is a highly innovative field. The past few decades have been characterized by rapid technological advances in the health care sector. Treatment has become more technology-intensive and expensive than ever before, and the introduction of new medical technologies has been regarded as a main cause of rising health-care expenditures. Contrary to other sectors of our economy where technology has often been associated with reduced costs, in the health sector technology is usually not perceived that way. As a result, health technology has come under scrutiny. Performance and cost considerations have been given more and more attention, and health technology assessment (HTA) has increasingly been perceived as a necessary function in efforts to achieve a more efficient health care system.

The principal aim of the work was to verify the effectiveness of the application of the well-known multicriterion decision-making Analytic Network Process technique (A.N.P.), to the assessment process of the health technologies.
\end{abstract}

Keywords: Analytic Network Process (ANP), Health Technology Assessment (HTA), health technology.

${ }^{*}$ Corresponding author 


\section{Introduction}

In this era of increasing cost pressures, restructuring of health care delivery and payment, and continued inadequate access to care for over tens people millions around the world, technology remains the substance of health care. Technology can be managed in ways that improve patient access and health outcomes, while continuing to encourage innovation. The development, adoption, and diffusion of technology is increasingly mediated by a widening group of policymakers in the health care sector. Health product makers, regulators, clinicians, patients, hospital managers, payers, government leaders, and others increasingly demand well-founded information to support decisions about whether or how to develop technology, to allow it on the market, acquire it, use it, to pay for its use, etc.

The pace of change in this field has presented an enormous challenge to the process of technology assessment of different medical devices.

One of the most important areas of intervention to support this process of re-engineering and streamlining different function in health care companies, hospitals and industries is Health Technology Assessment (HTA), a technical-scientific methodology, applicable in the institutional, political and clinical fields to ensure the government and the sustainability of innovations in health systems. HTA examines the short- and long-term social consequences of the application or use of technology.

The HTA is a multidimensional and multidisciplinary approach to analyze medical and clinical implications, social, organizational, economic, ethical and legal technology through the assessment of multiple dimensions such as efficacy, safety, costs, social and organizational impact.

The HTA approach integrated with ANP analysis was chosen over other methods because it allows to assign a specific weight to different aspects such as quality-related health technology assessment.

\section{Methodology: an integrated model ANP - HTA}

The study will develop a new methodological approach: ANP-HTA model or Integrated HTA. It is a decision making analysis based on qualitative and quantitative aspects with dependence and feedback and it is articulated in different steps as shown Figure 1:

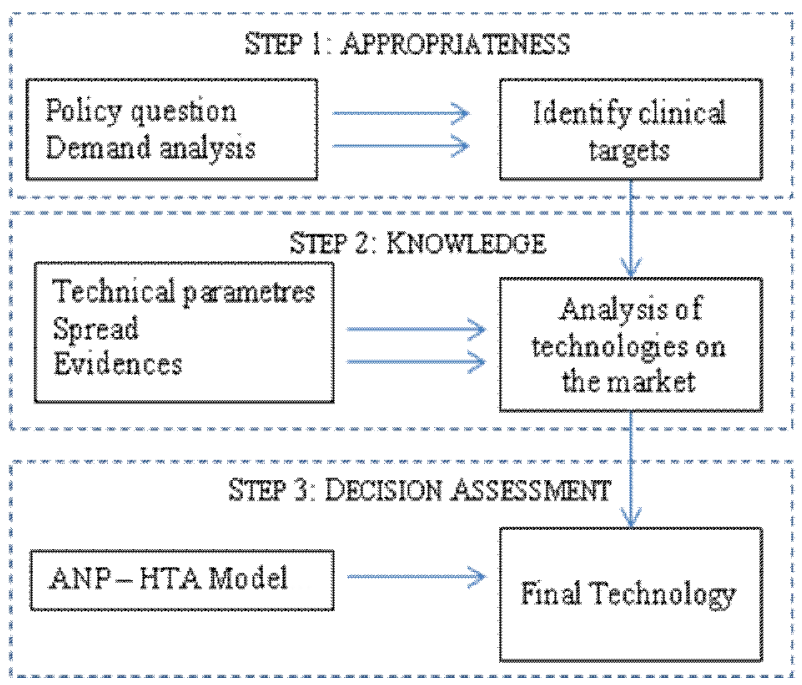

Figure 1: Steps

The aim of the study is define an integrated HTA to identify the appropriate health technology. 
Traditional HTA process is based on the following parameters:

- Safety.

- Efficacy/Effectiveness.

- Psycological/social/ethical aspects.

- Organizational/professional aspects.

- Economic aspects.

But, current HTA efforts are insufficient to meet the needs of policy makers within the health care system and should be expanded. This is due to several factors, including the fact that the level and scope of assessments are generally limited; that assessments are not sufficiently comprehensive with respect to their analysis of economic social, legal and/or ethical issues; that there is a lack of research on the relationship between health technologies and health outcomes; and that not enough attention is paid to identifying and setting priorities for assessment, particularly across jurisdictions.

The decision making process linked to HTA methods is very complex. Infact, it is necessary consider a great number of variables.

We need a way to determine which objective outweighs another, both in the near and long terms. Since we are concerned with real-life problems we must recognize the necessity for tradeoffs to best serve the common interest.

Individual knowledge and experience are inadequate in making decisions concerning the welfare and quality of life for a group or for individuals. Participation and debate are needed both among individuals and between the groups affected. Here two aspects of group decision making have to be considered.

The ANP-HTA model's goal is to identify the best alternative of health technologies.

The following table shaws parameters and sub-parametres:

\begin{tabular}{|l|l|l|}
\hline \multicolumn{2}{|l|}{ Parametres - Criteria } & Main sub-parametres - Sub Criteria \\
\hline C1 & Safety & $\begin{array}{l}\text { Risk Analysis } \\
\text { Human Factors Engineering and } \\
\text { Ergonomics } \\
\text { Technical Assistance }\end{array}$ \\
\hline C2 & Efficacy/Effectiveness & $\begin{array}{l}\text { Evidence Based Medicine (EBM) } \\
\text { Scientific documentation } \\
\text { Epidemiology - Statistical Report }\end{array}$ \\
\hline C3 & Psycological/social/ethical aspects & $\begin{array}{l}\text { Legislation - Government } \\
\text { Community needs }\end{array}$ \\
\hline C4 & $\begin{array}{l}\text { Organizational/professional/technical } \\
\text { and engineering aspects }\end{array}$ & $\begin{array}{l}\text { Governance } \\
\text { Training } \\
\text { Human Resourse } \\
\text { ICT, plant and structural requirements } \\
\text { Technical documentation }\end{array}$ \\
\hline C5 & Economic aspects & $\begin{array}{l}\text { Cost-Utily Analysis (QUALY) } \\
\text { Budget Impact Analysis }\end{array}$ \\
\hline
\end{tabular}

The purpose of the integrated model is to translate both technical and scientific information with a variety of economic, social, ethical and other context-specific factors into language that policy makers understand and with which they are comfortable. 


\section{Application of methodology: case study}

The methodology proposed makes the decision process more effective, equitable, sustainable and safety.

The Integrated HTA provides advice to decision makers at three levels:

- The macro level (government) or the level at which health policies are made. At this level decision makers plan and organize services, regulate the introduction and use of these technologies, and make coverage and reimbursement decisions.

- The meso level (hospitals) or the institutional management level. It is at this level that acquisition and monitoring questions are made.

- The micro level (providers of health care) or the clinical practice level at which the quality of the assessment is evaluated and at which clinical practice guidelines are established.

The Integrated HTA can be applied for a variety of reasons, including to:

- Make decisions about program funding, continuation of a program or program delivery.

- Make changes in clinical practice guidelines.

- Replace obsolete equipment or justify the introduction of a new type of technology and ensure that cost-effective technologies replace other technologies.

- Choose among different types of available technologies.

- Classify the stage of development of new technologies and limit over-enthusiastic, early use of developing technologies.

- Prevent widespread application of useless or harmful technologies.

- Avoid the purchase of new technologies that will not be used for lack of human or financial resources to operate them and/or ensure that new technologies are provided in amounts that correspond to health care needs and that they are appropriately located.

- Refer patients for treatment outside the province when a technology is not available in that province; and/or provide a basis for coverage decisions.

In order to validate the methodology proposed, it has been applied to the meso level decision.

In particular, the ANP-AHP model was applied in the decision making process of a new Diagnostic Clinical Center.

The purpose of the Center was first choose the best health technology among different classes and then to identify the best technology in the same class.

This paper illustrates only the decision process of the "2D and 3D Dental Imagin System".

Table 1: Synthesis of characteristics of the technologies analysed.

\begin{tabular}{|l|l|}
\hline Type of Technology & \multicolumn{1}{|c|}{ Characteristics } \\
\hline A1. Technology 1 & $\begin{array}{l}\text { Access to 3D technology at all dental professionals at an } \\
\text { affordable price maximizes ROI with localized field of view } \\
\text { for high resolution images. }\end{array}$ \\
& $\begin{array}{l}\text { Dedicate 3D imaging sensor } \\
\text { - Local dental applications } \\
\text { compared to larger field 3D systems } \\
\text { compact design }\end{array}$ \\
\hline A2. Technology 2 & $\begin{array}{l}\text { The 3D technology offer different imaging modes for different } \\
\text { needs. } \\
\text { The basic volumes can also be stitched together to generate a } \\
\text { larger view of patient anatomy }\end{array}$ \\
\hline
\end{tabular}




\begin{tabular}{|l|l|}
\hline & $\begin{array}{l}\text { - Technology enables free image geometry formation } \\
\end{array}$ \\
\hline & - 3 dedicate sensor \\
\hline A3. Technology 3 & $\begin{array}{c}\text { The } 3 \mathrm{D} \text { image volume range covers everything between single } \\
\text { tooth and whole facial region. } \\
-\quad \text { High initial investment } \\
-\quad \text { Good technical assistance requirements }\end{array}$ \\
\hline
\end{tabular}

A detailed file-card was drawn up which describes the technical characteristics and the advantages brought, permitting to attribute the loads in a non ambiguous way.

After defining the network, the method suggested requires comparison: system of pairwise comparisons's to used measure the weights of the components of the structure, and finally to rank the alternatives in the decision.

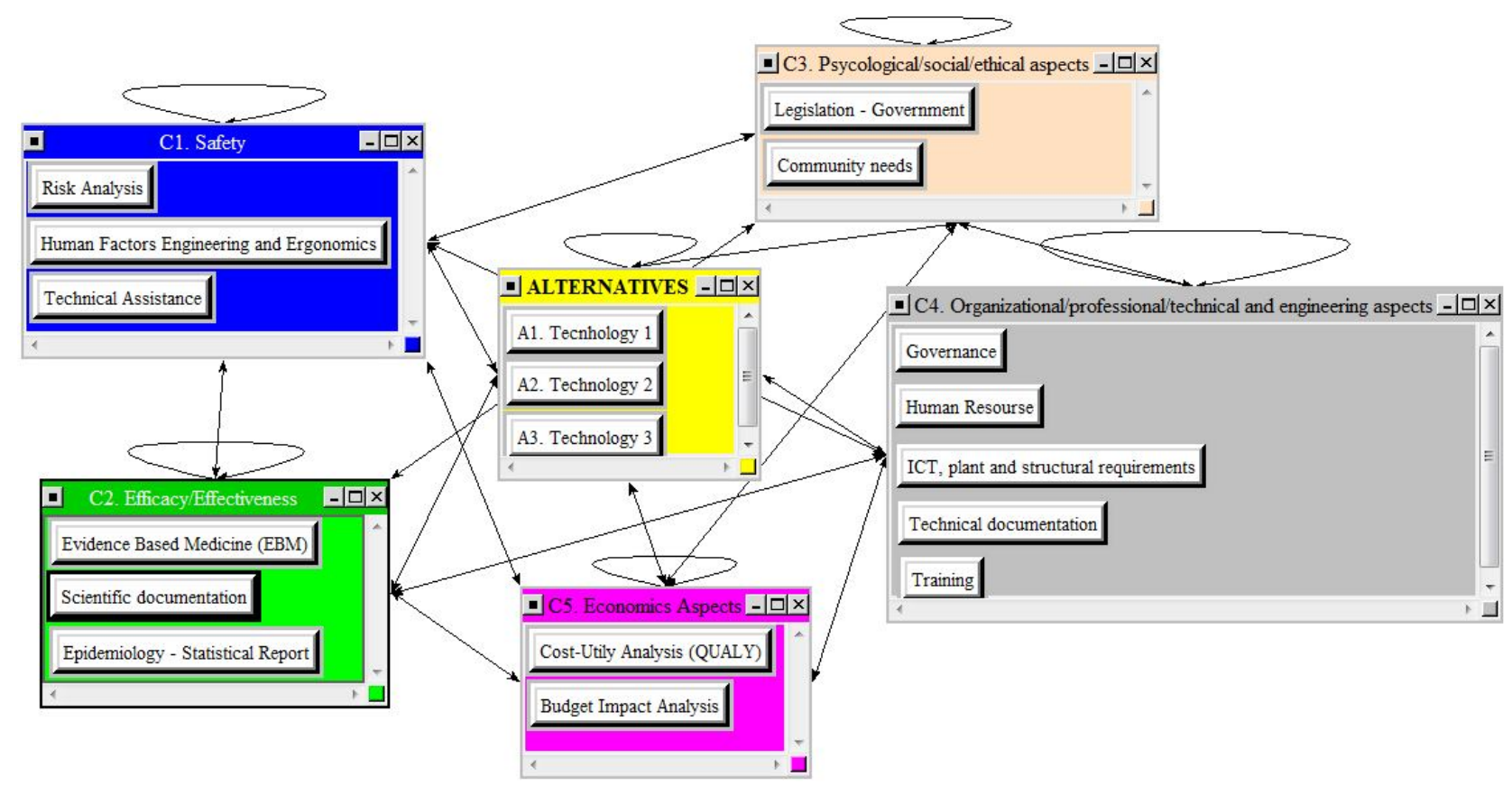

Figure 2: ANP-HTA Model

\section{Analysis of the results and conclusion}

The introduction of the ANP to HTA makes the decision methodology "dynamic", in the sense that it enables not only to consider different factors at the same time, but also to consider the same factors in different settings.

From the analysis of the results it is evident that the best choice consists in adopting Technology 2 . 
Table 2: Results

\begin{tabular}{|l|l|}
\hline Alternatives & Priorities \\
\hline A1. Tecnhology 1 & 0.302298 \\
\hline A2. Technology 2 & 0.385756 \\
\hline A3. Technology 3 & 0.339599 \\
\hline
\end{tabular}

The value of the consistency index is less than 0.1 , which guarantees the congruency of the judgements collected and used for the analysis.

Figure 3 shows the "sensibility analysis" realized in order to observe the importance of an alternative to the changing of the priority vector



Figure 3: "Sensibility analysis"

Ultimately, the application of the AHP-HTA model has led to the optimal choice for the health technology, whose synthesis is represented by the interventions defined by the "priority vector".

\section{REFERENCES}

A.Cicchetti, M. Marchetti (2010). Manuale di health technology assessment. Il Pensiero Scientifico.

Ricciardi W., Agostinelli A., La Torre G., Cicchetti A., Derrico P., Patarnello F.. Primo Libro Binco sull'Health Technology Assessmnet in Italia. 
Ricciardi W., La Torre G. (2010). Health technology assessment. Principi, dimensioni e strumenti. Ed. SEEd.

F. De Felice A. Petrillo, Proposal of a new model for the optimization of the organizational process in industrial company through the application of the Analytic Network Process. Proceedings of the International Conference on Modelling \& Applied Simulation, Porto de la Cruz (Tenerife), 23-25 September, 2009.

Saaty, T.L., (1980). The Analytic Hierarchy Process. McGraw-Hill, New York NY.

Saaty, T.L., (2001). Decision making with independence and feedback: The Analytic Network Process, Pittsburgh, RWS Publications.

Saaty, T.L. (2005). Theory and Applications of the Analytic network Process: decision making with benefits, opportunities, costs, and risks. Pittsburg, PA: RWS Publications.

A. Francesconi (2007). Innovazione organizzativa e tecnologica in sanità. Il ruolo dell'health technology assessment. Ed. Franco Angeli. 